\title{
LA-UR-12-23423
}

Approved for public release; distribution is unlimited.

Title:

Author(s):

\section{Electron Backscatter Diffraction (EBSD) Characterization of Uranium and Uranium Alloys}

\author{
McCabe, Rodney J. \\ Kelly, Ann Marie \\ Clarke, Amy J. \\ Field, Robert D. \\ Wenk, H. R.
}

Intended for:
Microscopy \& Microanalysis 2012, 2012-07-29/2012-08-02 (Phoenix, Arizona, United States)

\section{- LOSAlamos \\ EST. 1943}

Disclaimer:

Los Alamos National Laboratory, an affirmative action/equal opportunity employer,is operated by the Los Alamos National

Security, LLC for the National NuclearSecurity Administration of the U.S. Department of Energy under contract DE-AC52-06NA25396. By approving this article, the publisher recognizes that the U.S. Government retains nonexclusive, royalty-free license to publish or reproduce the published form of this contribution, or to allow others to do so, for U.S. Government purposes.

Los Alamos National Laboratory requests that the publisher identify this article as work performed under the auspices of the

U.S. Departmentof Energy. Los Alamos National Laboratory strongly supports academic freedom and a researcher's right to publish; as an institution, however, the Laboratory does not endorse the viewpoint of a publication or guarantee its technical correctness. 


\title{
Electron Backscatter Diffraction (EBSD) Characterization of Uranium and Uranium Alloys
}

\author{
R. J. McCabe ${ }^{1}$, A. M. Kelly ${ }^{1}$, A. J. Clarke ${ }^{1}$, R.D. Field ${ }^{1}$, H.R. Wenk ${ }^{2}$ \\ ${ }^{1}$ Los Alamos National Laboratory, Los Alamos, NM 87544 USA \\ ${ }^{2}$ University of California, Berkely, CA, 94720 USA
}

Electron backscatter diffraction (EBSD) was used to examine the microstructures of unalloyed uranium, U-6Nb, U-10Mo, and U-0.75Ti. For unalloyed uranium, we used EBSD to examine the effects of various processes on microstructures including casting, rolling and forming, recrystallization, welding, and quasi-static and shock deformation. For U-6Nb we used EBSD to examine the microstructural evolution during shape memory loading. EBSD was used to study chemical homogenization in U-10Mo, and for U-0.75Ti, we used EBSD to study the microstructure and texture evolution during thermal cycling and deformation.

The studied uranium alloys have significant microstructural and chemical differences and each of these alloys presents unique preparation challenges. Each of the alloys is prepared by a sequence of mechanical grinding and polishing followed by electropolishing with subtle differences between the alloys. U-6Nb and U-0.75Ti both have martensitic microstructures and both require special care in order to avoid mechanical polishing artifacts. Unalloyed uranium has a tendency to rapidly oxidize when exposed to air and a two-step electropolish is employed, the first step to remove the damaged surface layer resulting from the mechanical preparation and the second step to passivate the surface. All of the alloying additions provide a level of surface passivation and different one and two step electropolishes are employed to create good EBSD surfaces.

Because of its low symmetry crystal structure, uranium exhibits complex deformation behavior including operation of multiple deformation twinning modes. EBSD was used to observe and quantify twinning contributions to deformation and to examine the fracture behavior. Figure 1 shows a cross section of two mating fracture surfaces in cast uranium showing the propensity of deformation twinning and intergranular fracture largely between dissimilarly oriented grains.

Deformation of U-6Nb in the shape memory regime occurs by the motion of twin boundaries formed during the martensitic transformation. Deformation actually results in a coarsening of the microstructure making EBSD more practical following a limited amount of strain. Figure 2 shows the microstructure resulting from 6\% compression.

Casting of U-10Mo results in considerable chemical segregation as is apparent in Figure 2a. The segregation subsists through rolling and heat treatment processes as shown in Figure 2b. EBSD was used to study the effects of homogenization time and temperature on chemical heterogeneity. It was found that times and temperatures that result in a chemically homogeneous microstructure also result in a significant increase in grain size.

U-0.75Ti forms an acicular martinsite as shown in Figure 4. This microstructure prevails through cycling into the higher temperature solid uranium phases. 


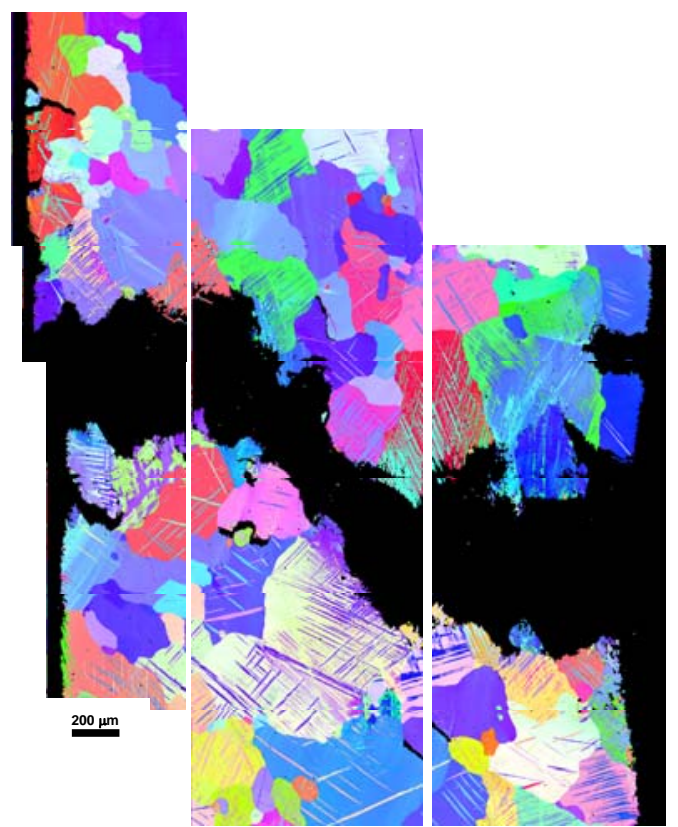

Figure 1. Cross section of mating fracture surfaces in an unalloyed uranium tensile specimen. Apparent is the prevalence of deformation twins and the intergranular fracture between grains of dissimilar orientation
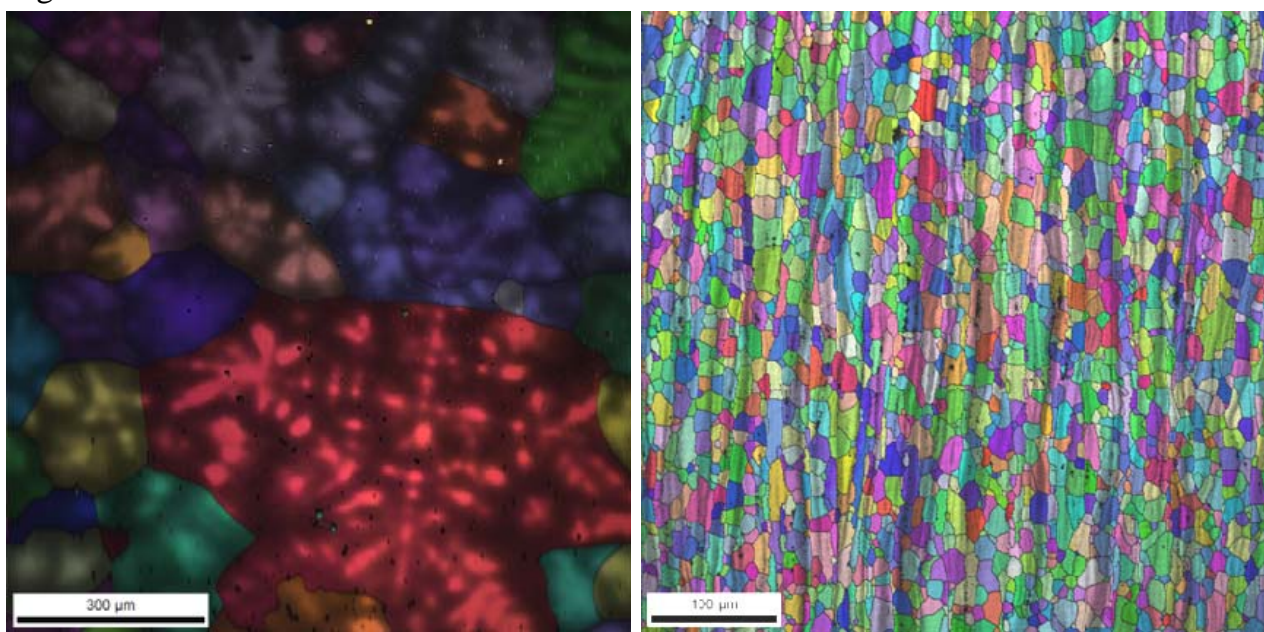

Figure 3. Microstructures of U-10Mo showing chemical segregation following a) casting and b) hot rolling and recrystallization.

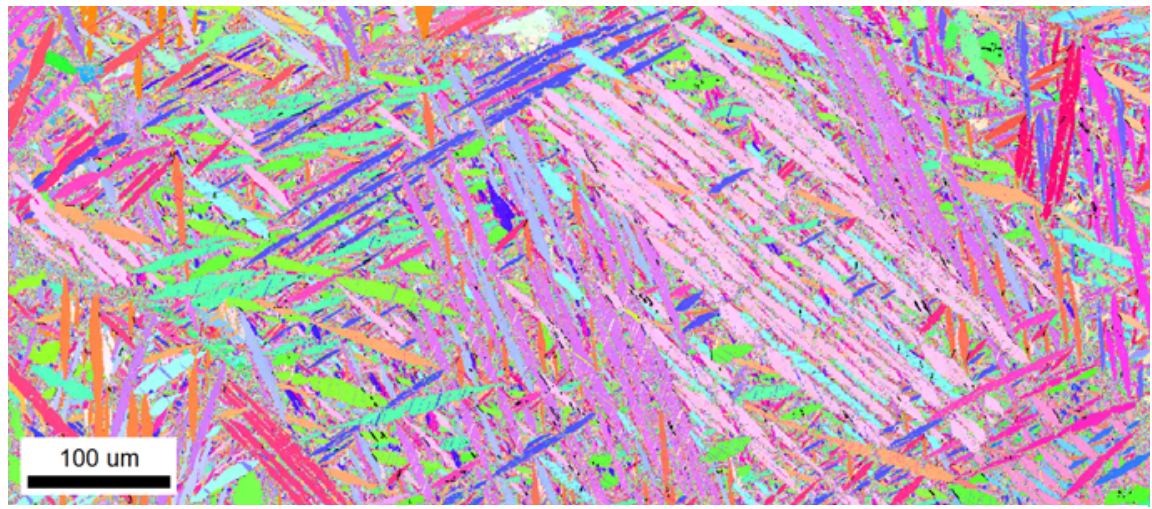

Figure 4. Acicular martensite observed in U-0.75Ti
Figure 2. Microstructure of U-6Nb following 6\% compressive deformation. 


\title{
Electron Backscatter Diffraction (EBSD) Characterization of Uranium and Uranium Alloys
}

\author{
R.J. McCabe, A.M. Kelly, A.J. Clarke, R.D. Field, H.R. Wenk \\ Materials Science \& Technology Division, Materials Technology - Metallurgy (MST-6) \\ Los Alamos National Laboratory
}




\section{EBSD of Uranium Alloys}

- Challenges

- Specimen preparation

- EBSD of Uranium Alloys

$>\mathrm{U}-10 \mathrm{Mo}$

$>\mathrm{U}-6 \mathrm{Nb}$

$>\mathrm{U}-0.75 \mathrm{Ti}$

$>$ Unalloyed Uranium 


\section{Uranium Alloy Challenges}

- Specimen handling

- Oxidation

- Microstructure

$>$ Unalloyed Uranium $>$ U-10Mo, U-6Nb, U$0.75 \mathrm{Ti}$
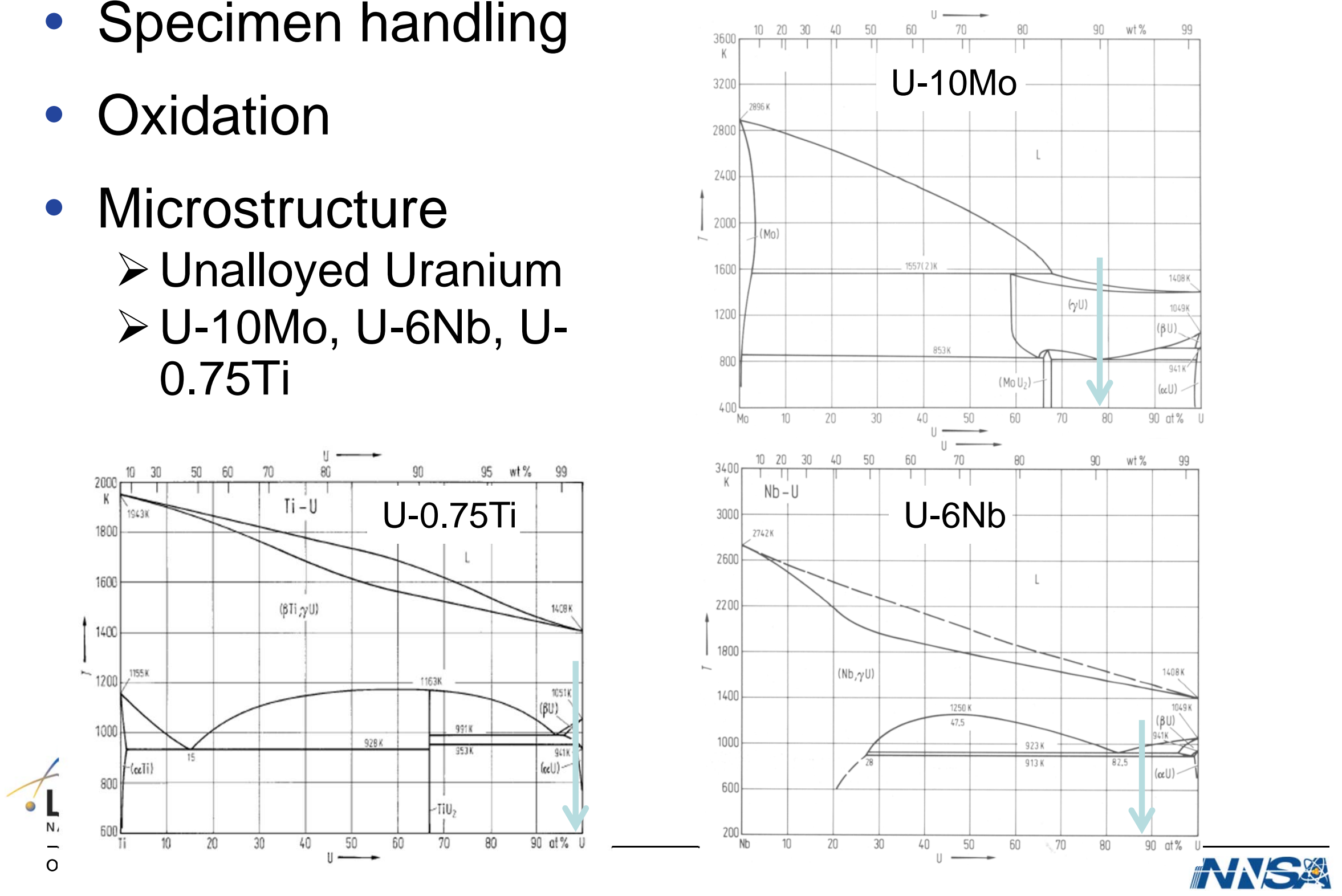


\section{Uranium Alloy Sample Preparation}

- Mechanical grinding/polishing to $1 \mu \mathrm{m}$ diamond - corotation for alloys at $1 \mu \mathrm{m}$

- Electropolish A

$>27 \mathrm{H}_{3} \mathrm{PO}_{4}$ : 45 ethanol : 27 ethylene glycol

$>10-20 \mathrm{~V}, 5-10$ minutes, stirred

- Electropolish $\mathrm{B}$

$>5 \mathrm{H}_{3} \mathrm{PO}_{4}: 95 \mathrm{H}_{2} \mathrm{O}$

$>5 \mathrm{~V}, 1-2$ seconds

- Electropolish $\mathrm{C}$

$>85 \mathrm{H}_{3} \mathrm{PO}_{4}: 2 \mathrm{H}_{2} \mathrm{SO}_{4}: 13 \mathrm{H}_{2} \mathrm{O}$ :

$>12 \mathrm{~V}, 5$ seconds 


\section{U-10Mo Alloy Fuels}

- Mo segregation in as-cast microstucture

$>-100 \mu \mathrm{m}$ grain size

- Segregation persists following hot rolling and annealing

- Typical BCC rolling texture
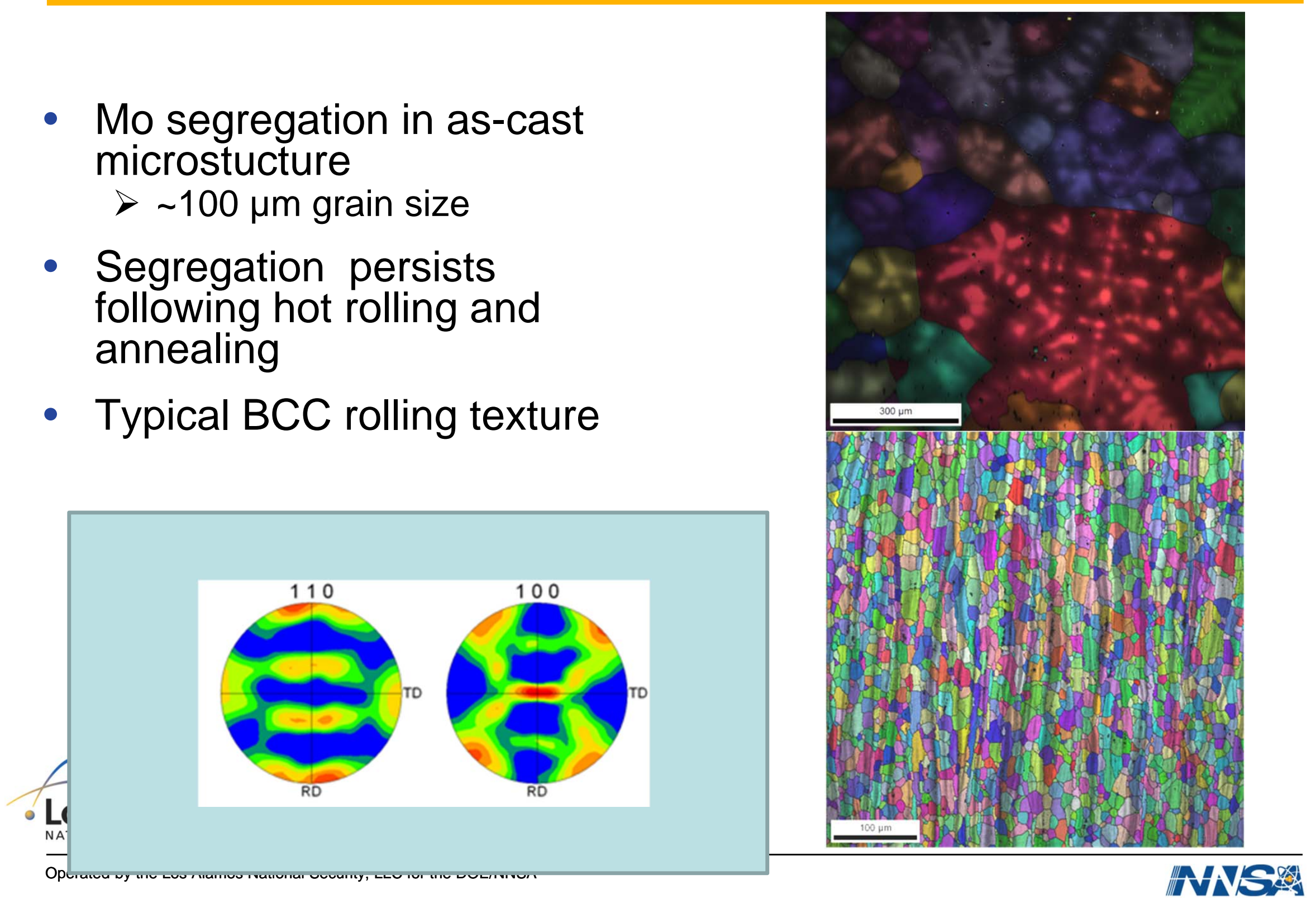


\section{U-10Mo Casting - Homogenization}
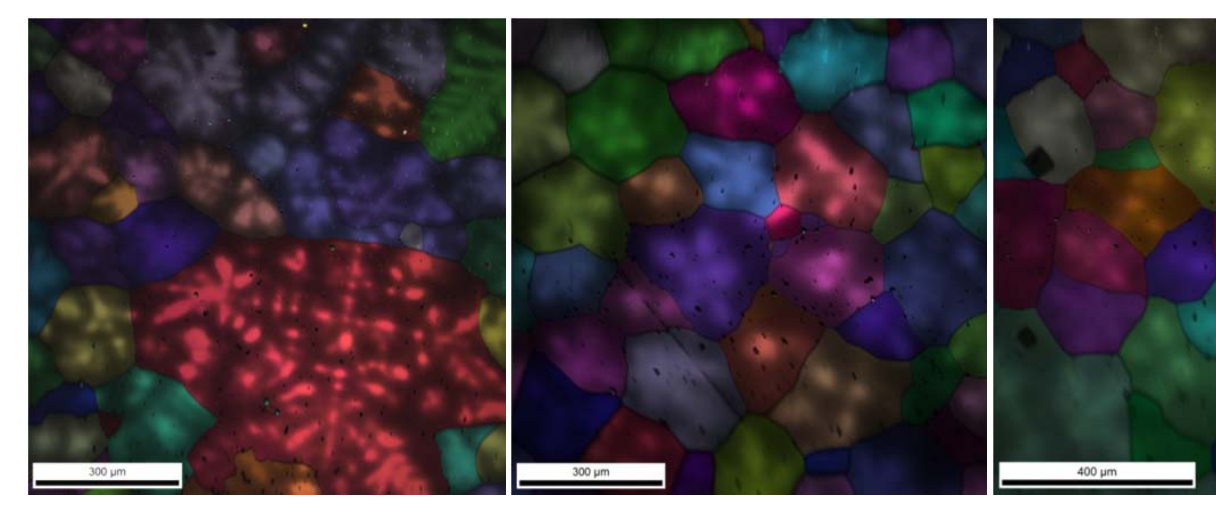

Cast
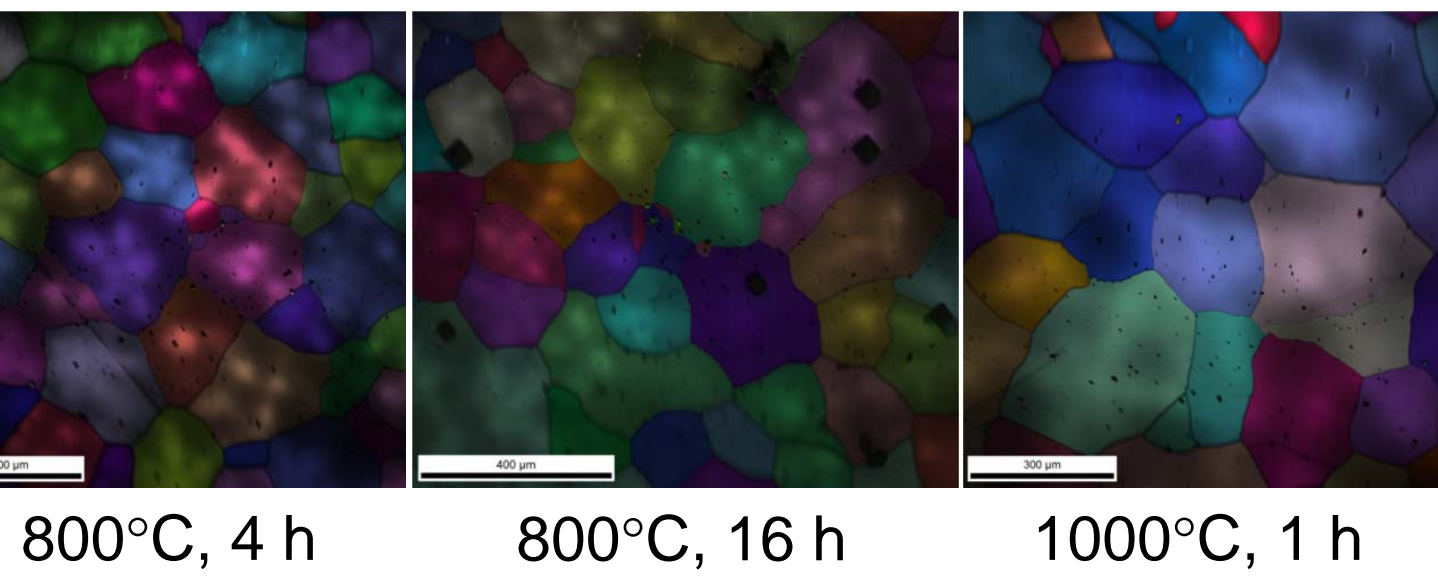

$1000^{\circ} \mathrm{C}, 1 \mathrm{~h}$
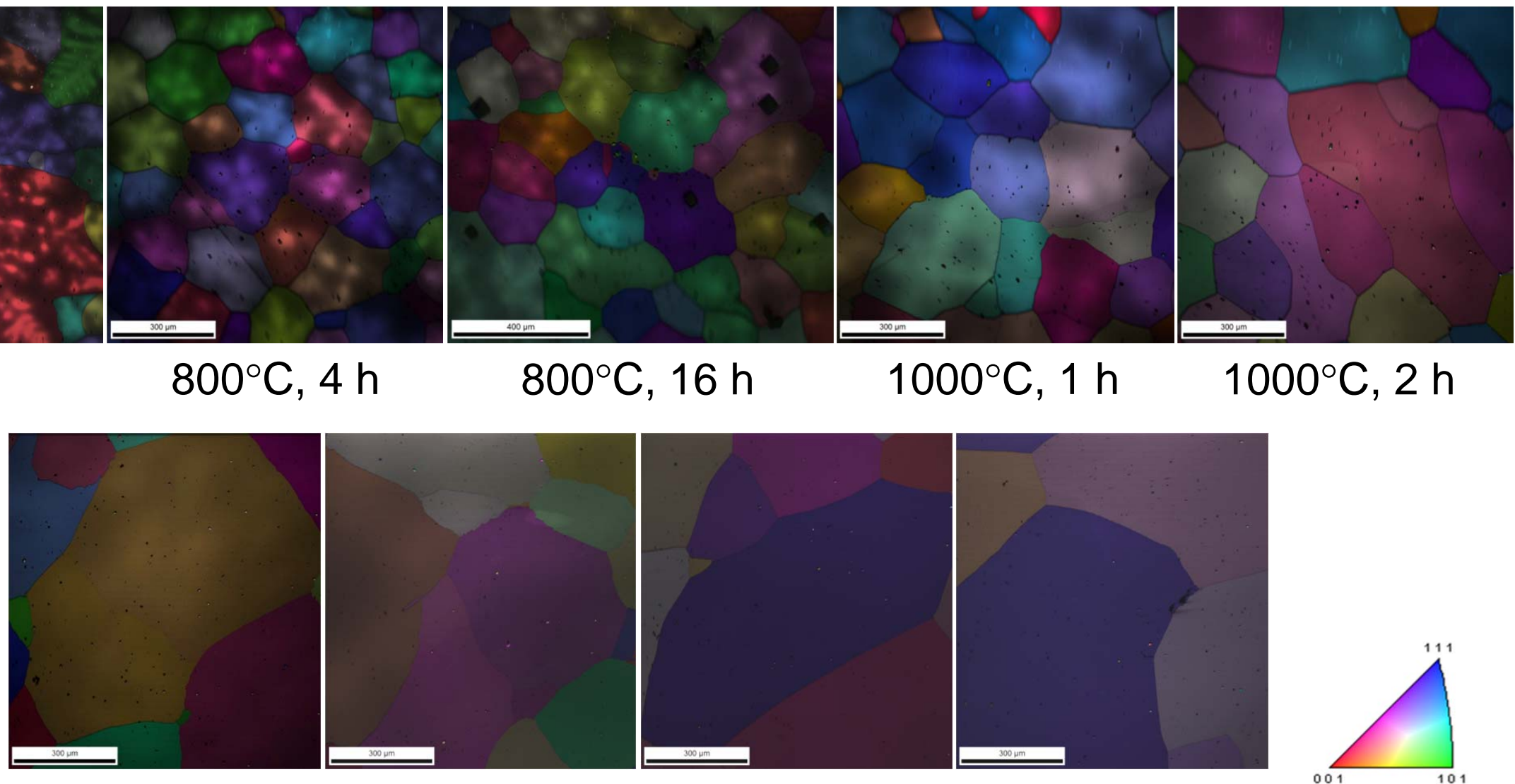

$1000^{\circ} \mathrm{C}, 4 \mathrm{~h}$

$1000^{\circ} \mathrm{C}, 8 \mathrm{~h}$
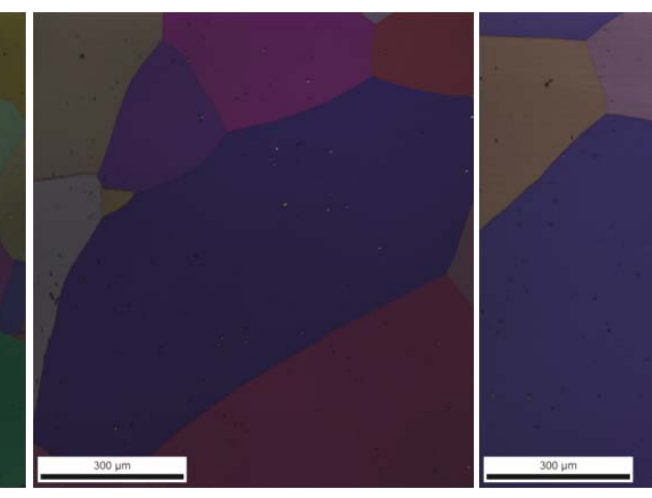

Los Alamos

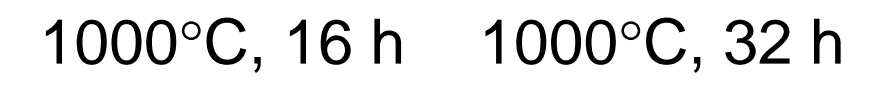

$1000^{\circ} \mathrm{C}, 2 \mathrm{~h}$ NATIONAL LABORATORY 


\section{U-6Nb Deformation}
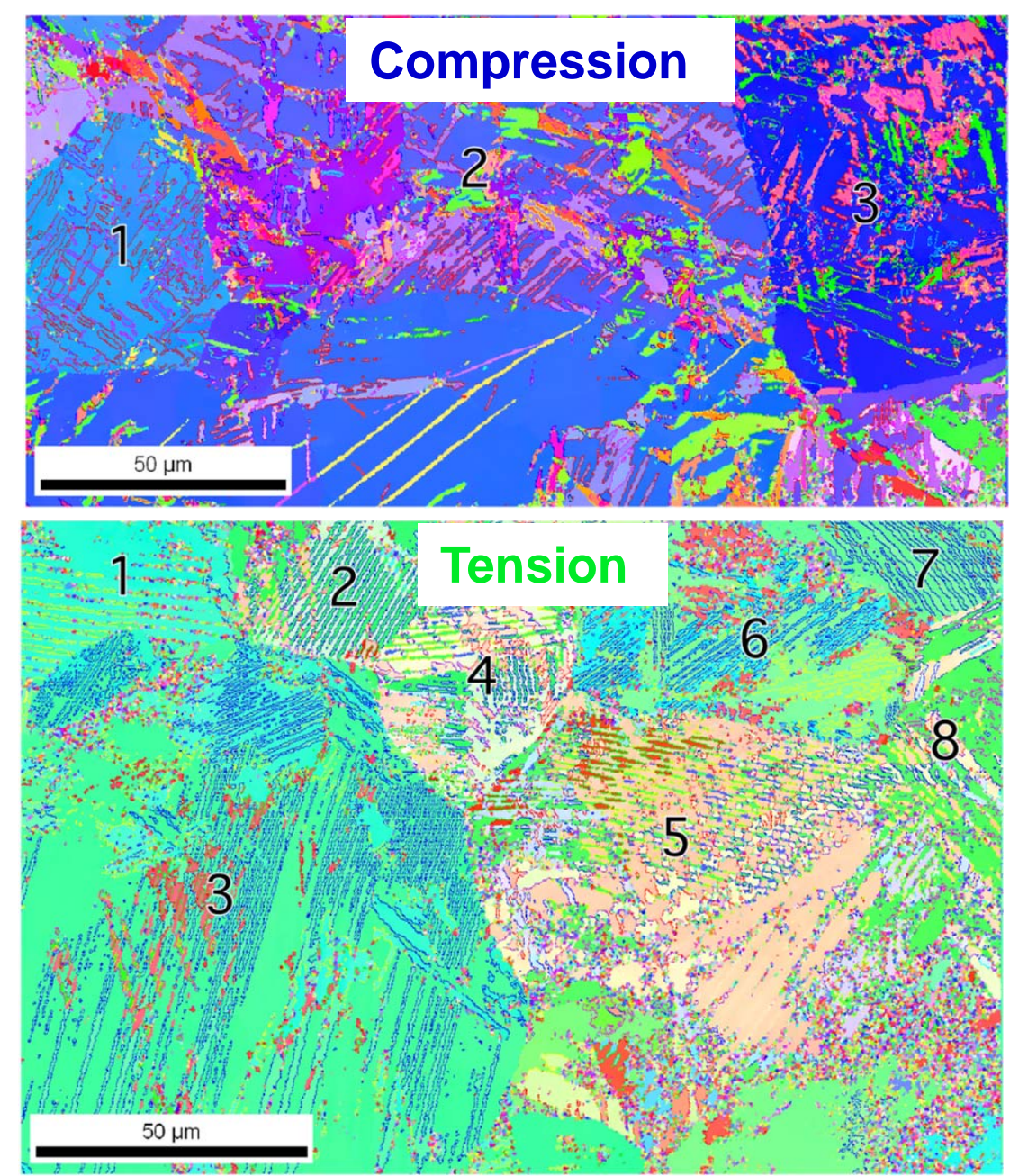

- Los Alamos

NATIONAL LABORATORY

Operated by the Los Alamos National Security, LLC for the DOE/NNSA $\gamma$ std. triangle for HV10

$\mathrm{MFV}^{*}$ in compression

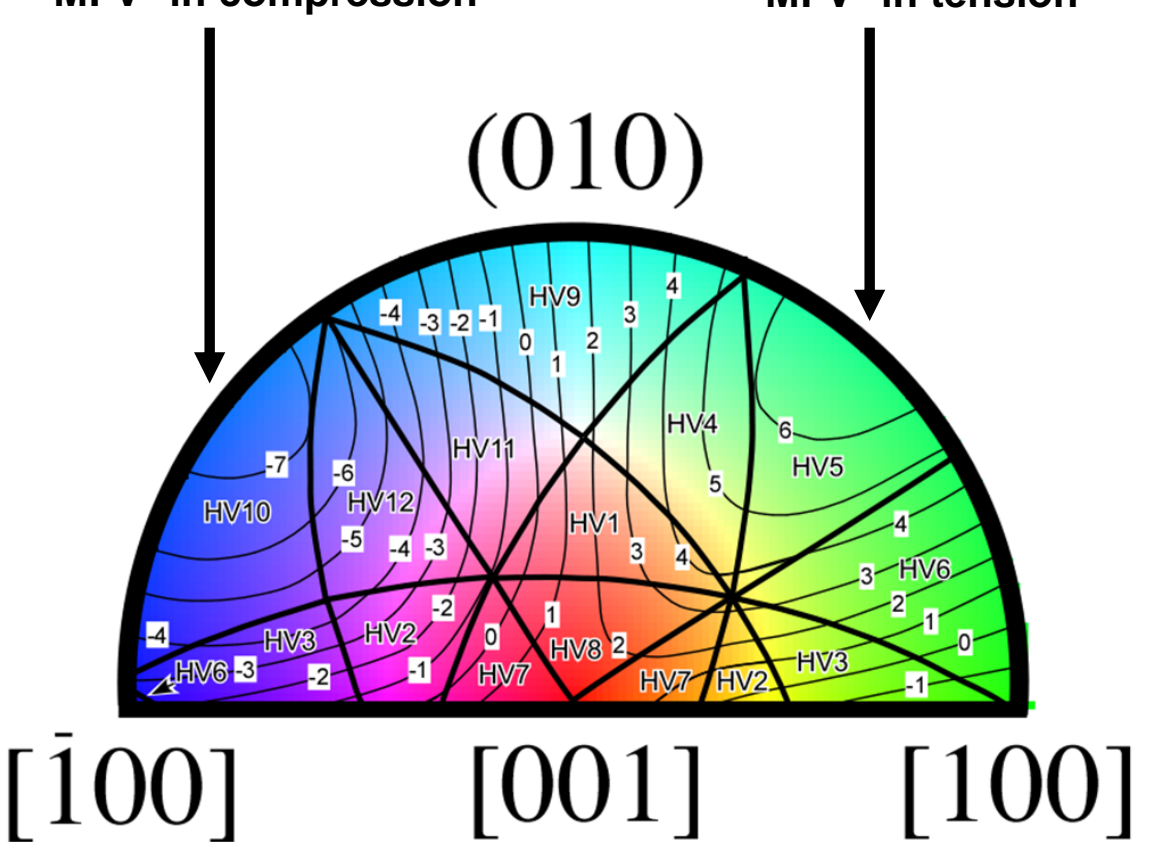

Martensite orientation color legend, position of $\gamma$ standard triangles for the 12 possible martensite Hatt $^{\dagger}$ variants (HVs) determined from the known orientation relationship, and calculated accommodation strain contours.

${ }^{\dagger}$ Hatt BA. J Nucl Mater 1966; 19:133

* Most Favored Variant $\gamma$ std. triangle for HV5 $\mathrm{MFV}^{*}$ in tension 


\section{U-6Nb: Micro-Pillar Testing}
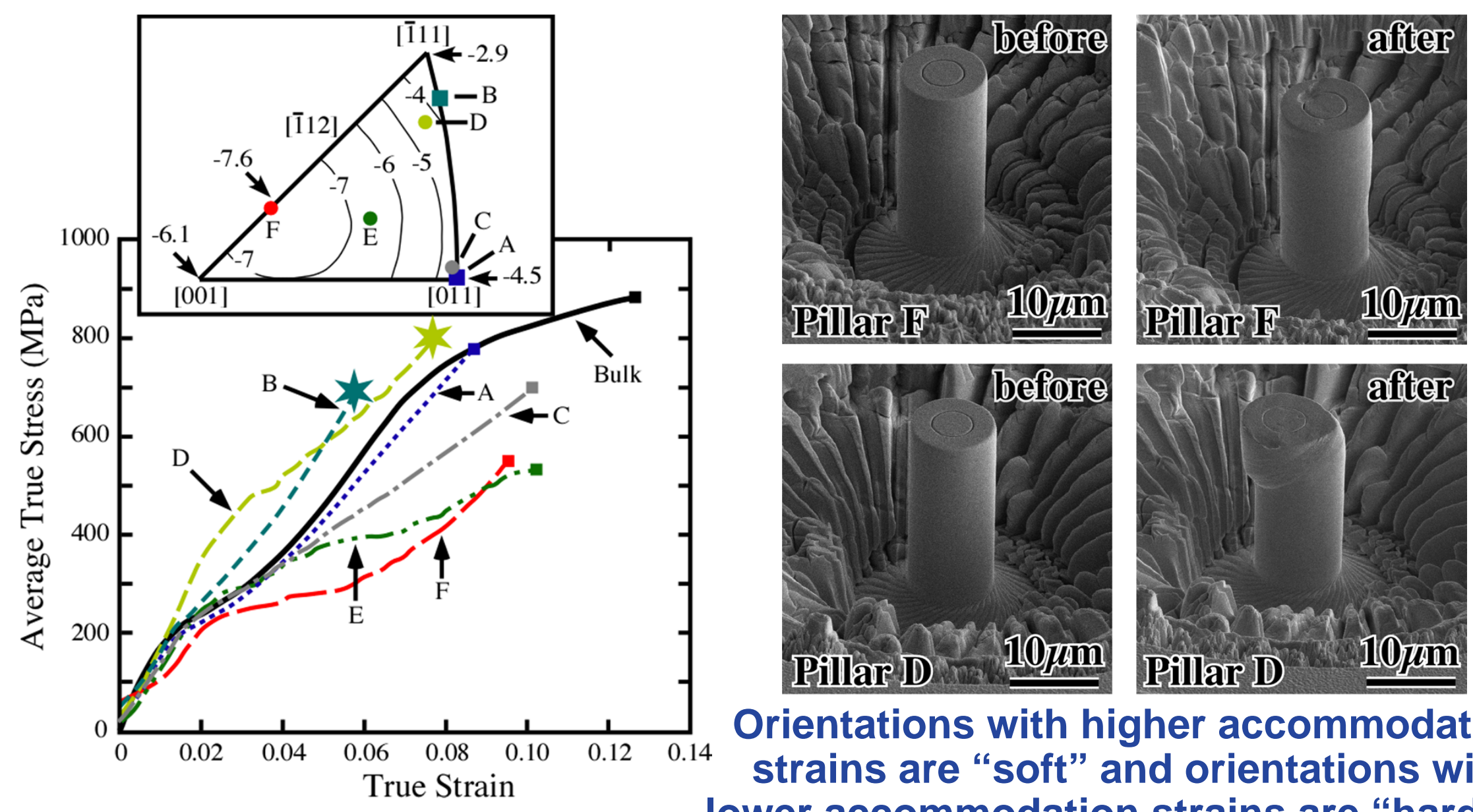

Orientations with higher accommodation strains are "soft" and orientations with lower accommodation strains are "hard", in agreement with single crystal predictions

\section{- Los Alamos




\section{U-0.75 Ti: Texture Memory}

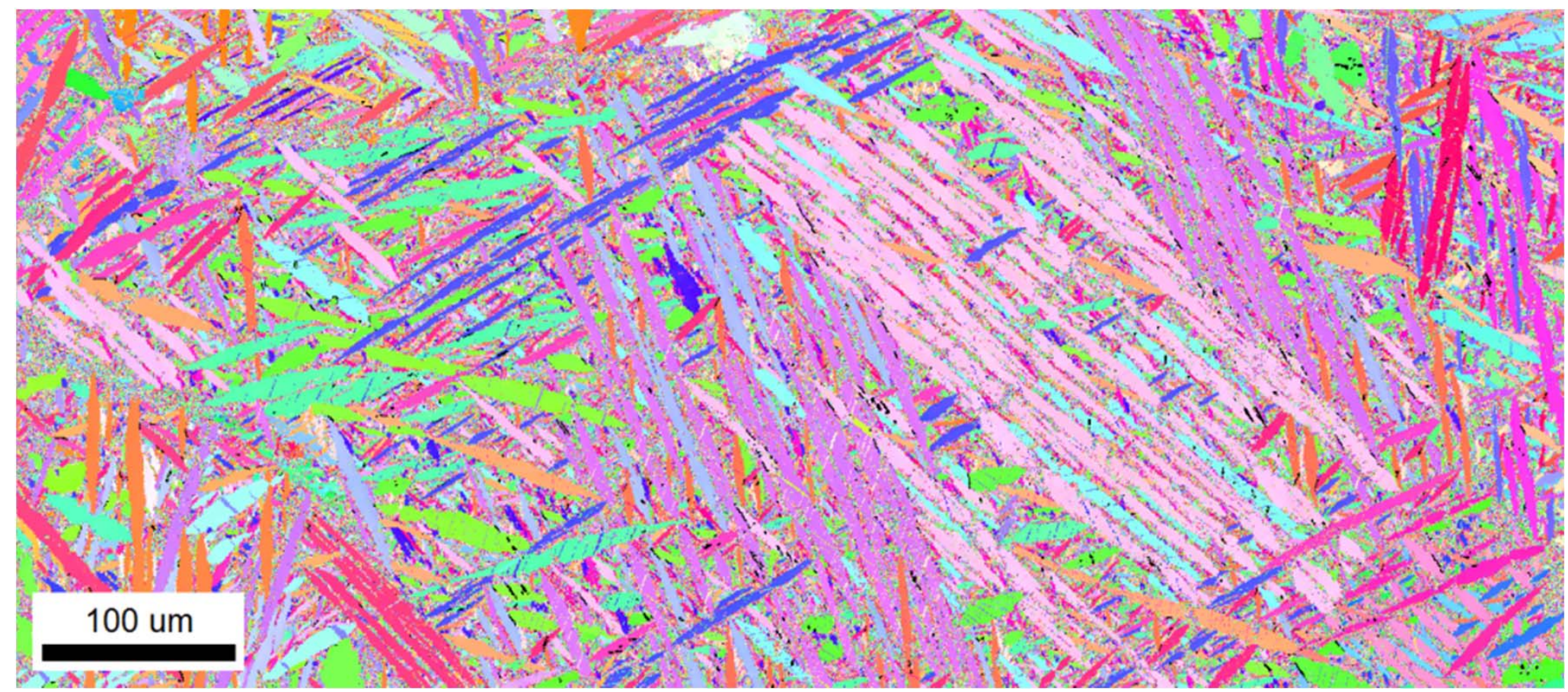

\section{- Los Alamos \\ NATIONAL LABORATORY}




\section{$\alpha$-Uranium}

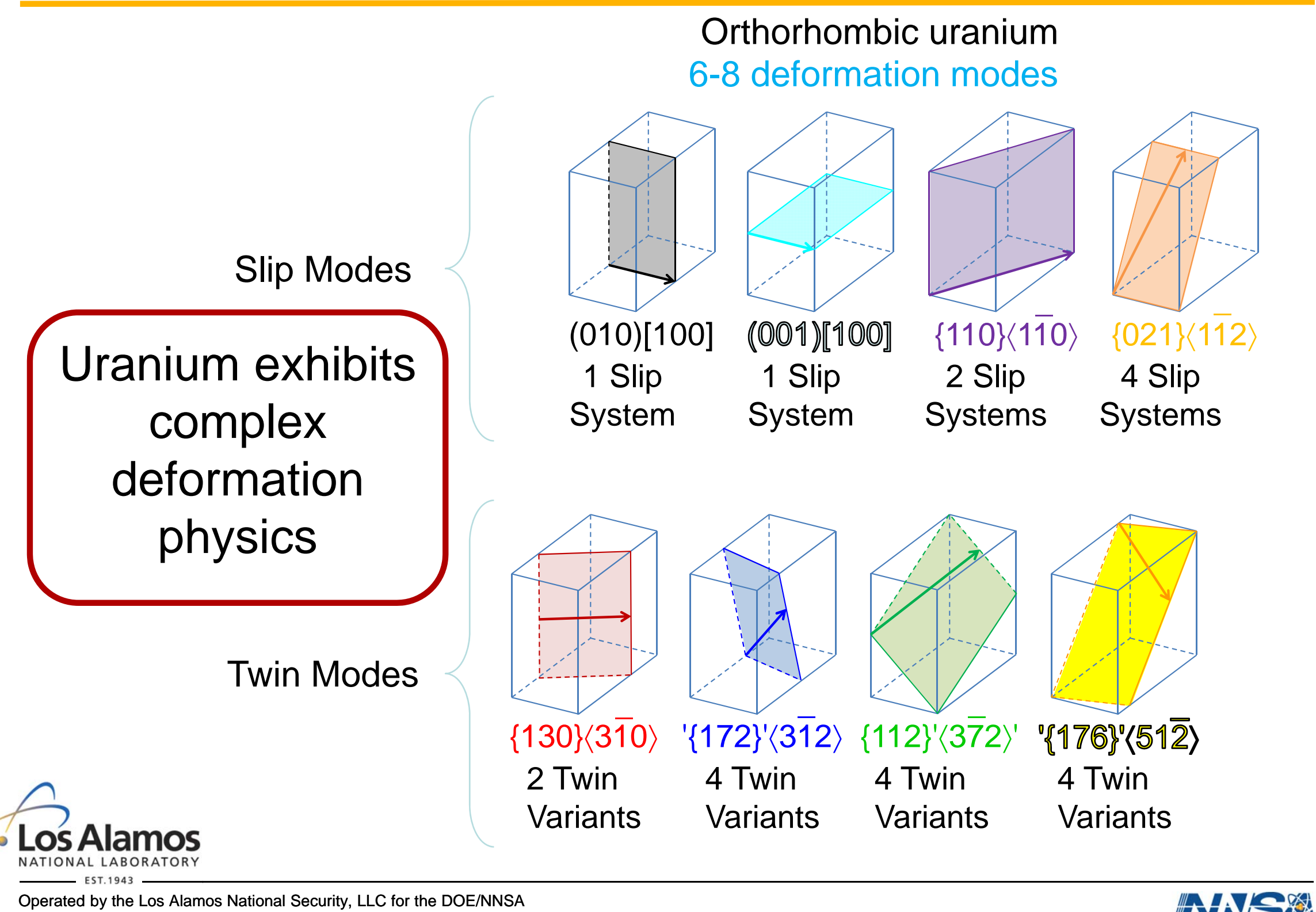




\section{$\alpha$-Uranium Deformation}
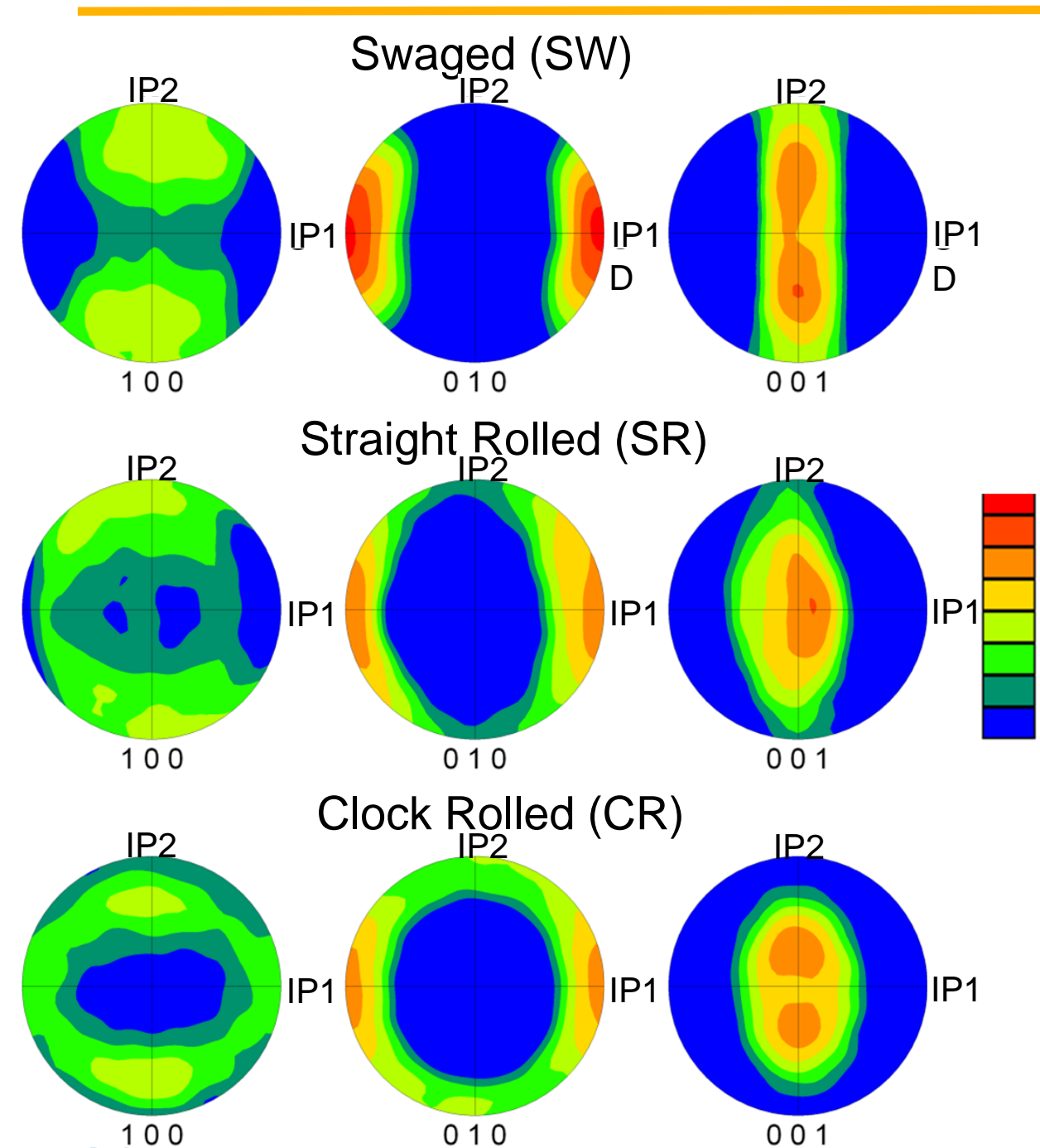

Clock Rolled (CR)
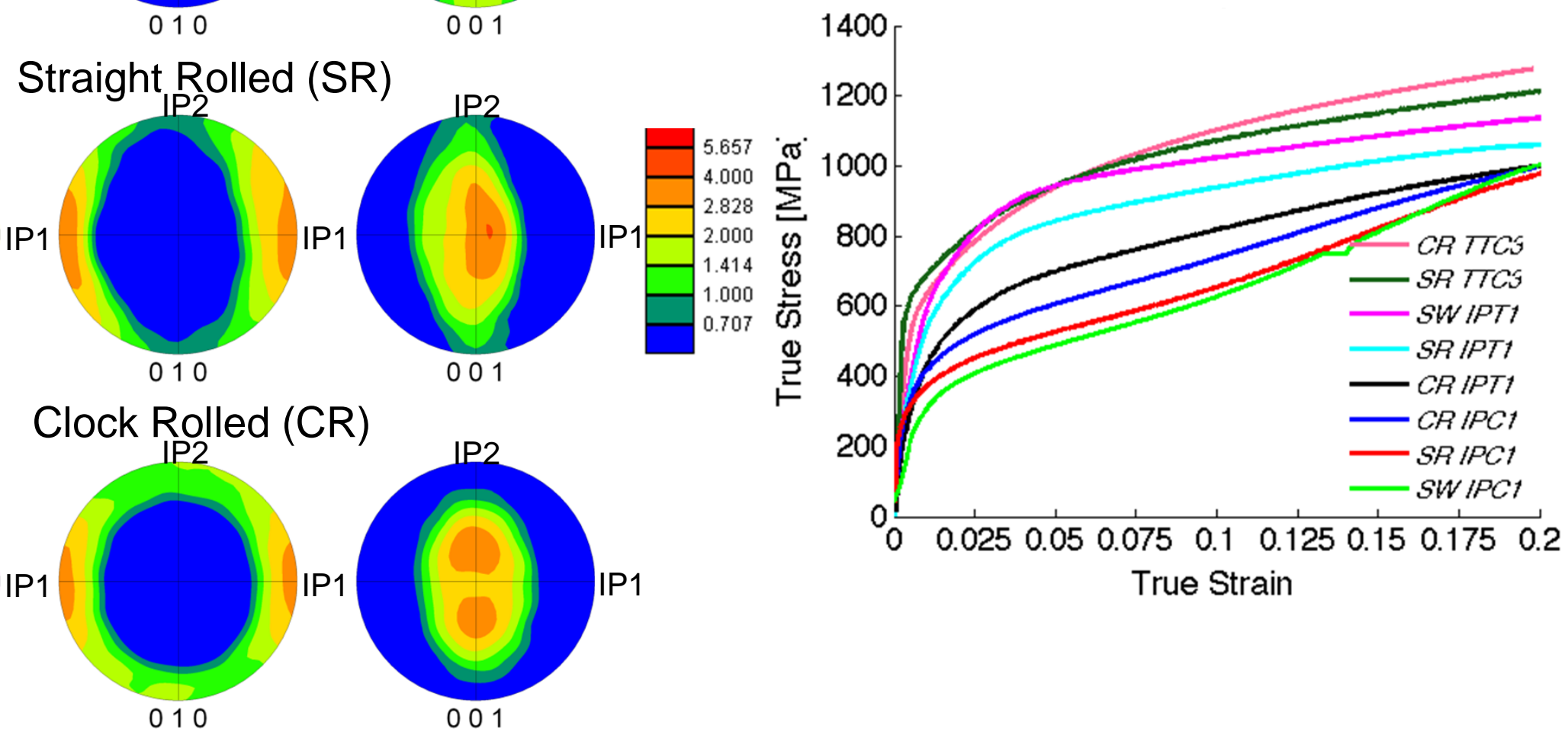

\section{- Los Alamos \\ NATIONAL LABORATORY}

Operated by the Los Alamos National Security, LLC for the DOE/NNSA 


\section{Uranium: Microstructure Change}

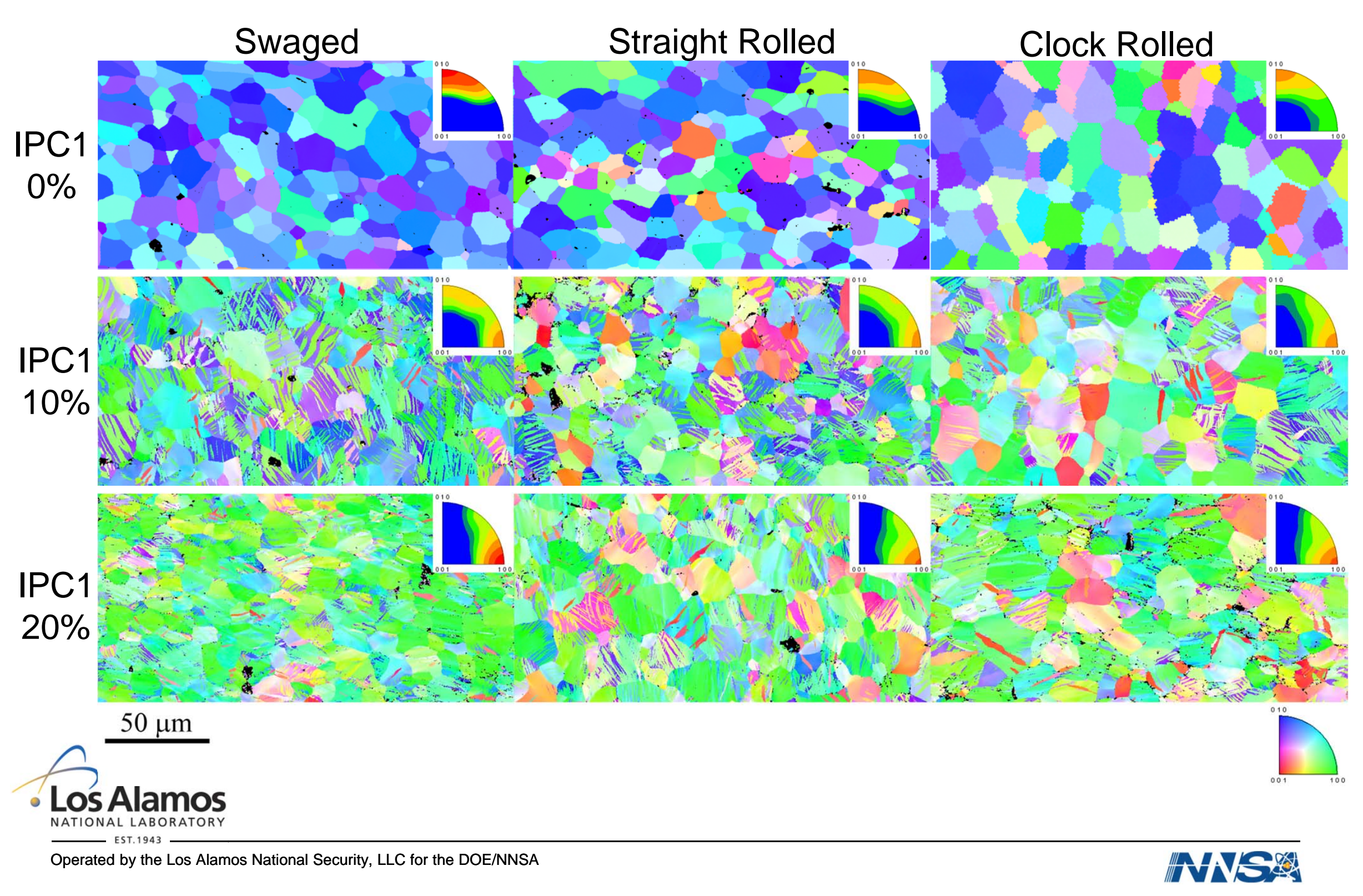




\section{Constitutive Law Development}
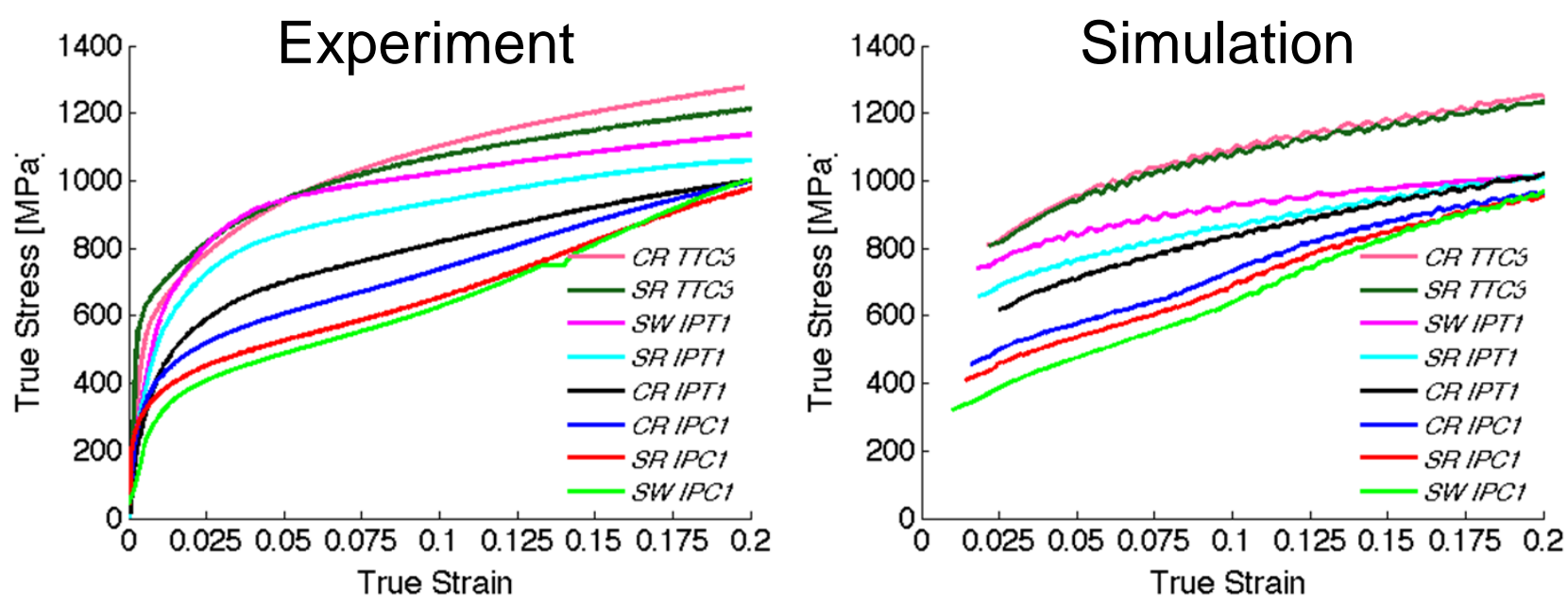

VPSC model predicts uranium anisotropic deformation behavior

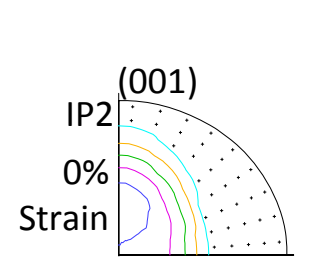

\section{Experiment}

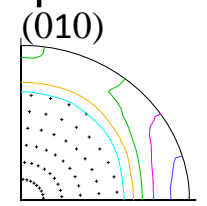

IP1
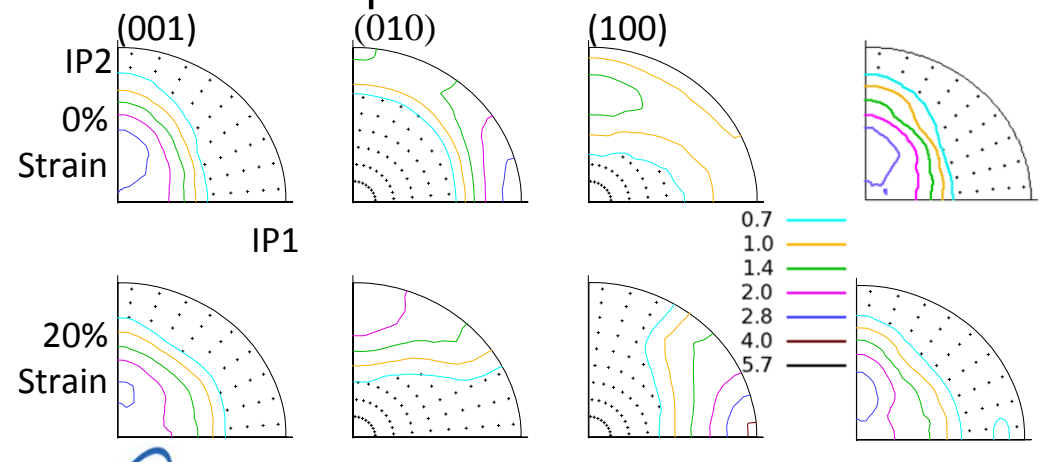

\section{Simulation}
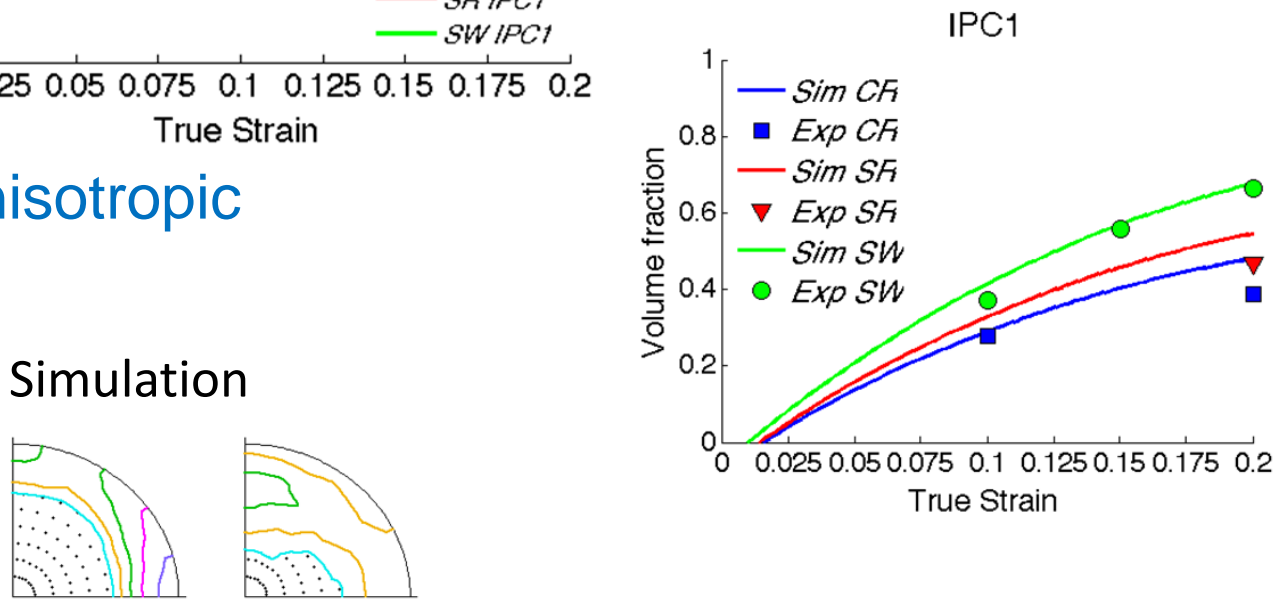

Pole figure texture plots for CR-IPC1 deformation showing that VPSC predicts microstructure evolution

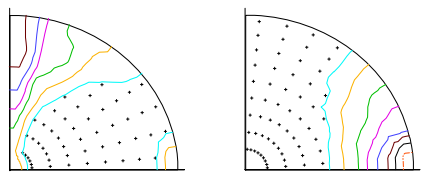




\section{Model Validation: Compression Geometry}
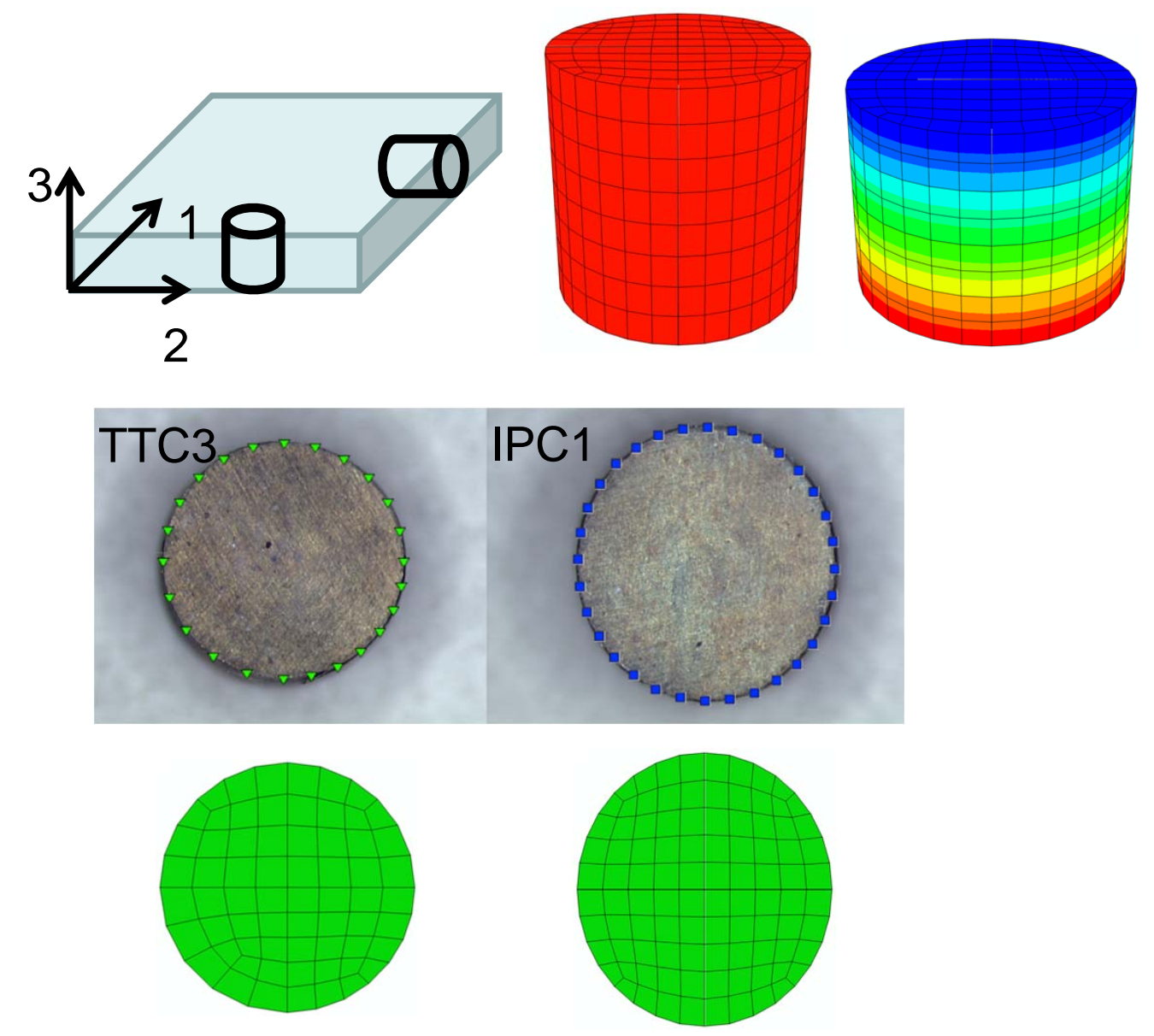

- Los Alamos NATIONAL LABORATORY 


\section{Model Validation: Bent Beams}

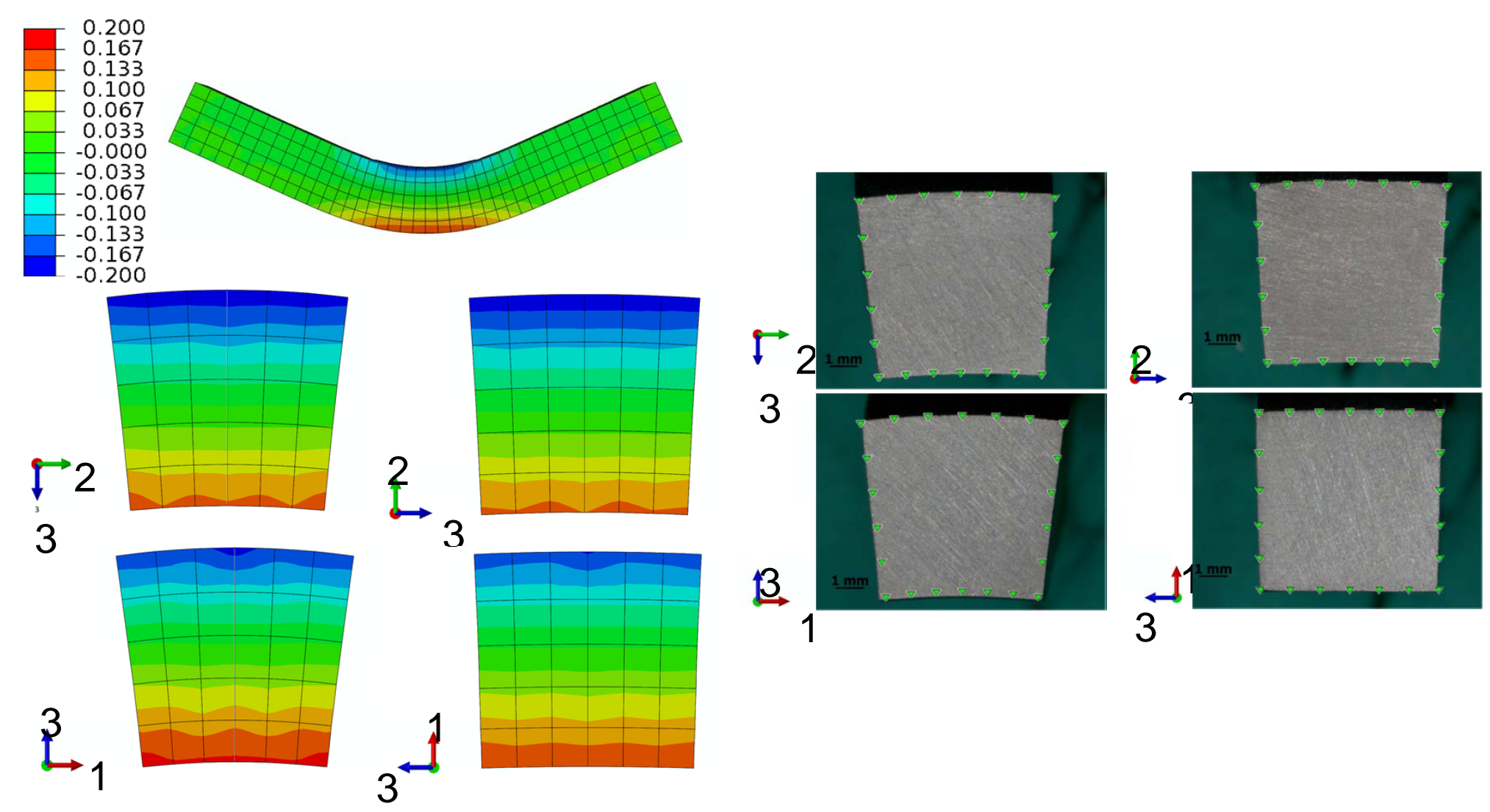

- LOS Alamos

Operated by the Los Alamos National Security, LLC for the DOE/NNSA

NIVS 


\section{$\alpha$-Uranium Fracture}

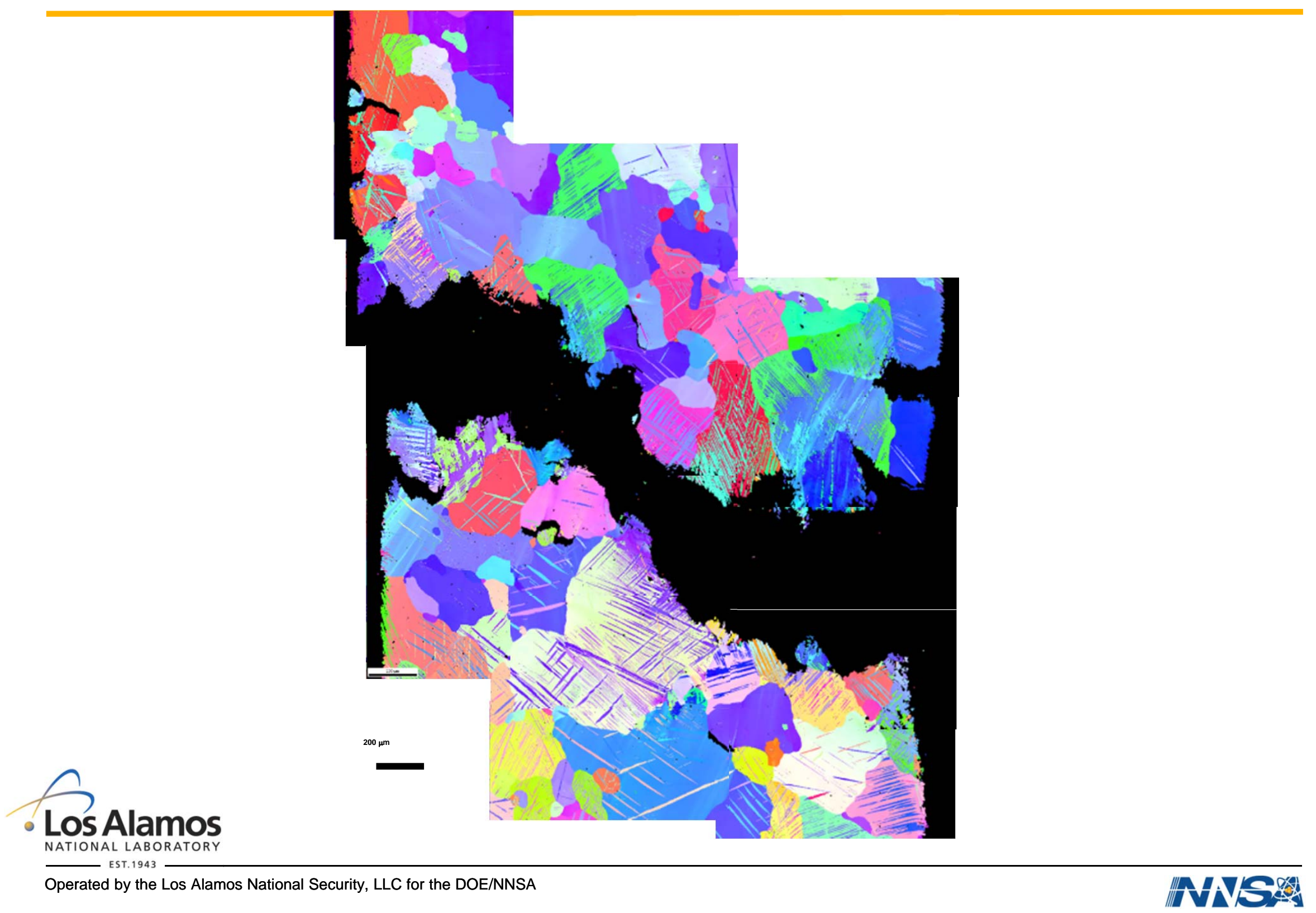




\section{Summary: EBSD of Uranium Alloys}

- We continue to improve in our ability to get good EBSD results for uranium alloys

- U-10Mo

$>$ Characterizing microstructural evolution for a new process

- U-6Nb

$>$ Corroboration of shape memory mechanical model

- Unalloyed Uranium

$>$ Development of uranium constitutive deformation law

$>$ Processing effects on microstructure 